\title{
Intracellular destruction of salmonellae in genetically resistant mice
}

\author{
F. R. LIN, H. S. HSU*, V. R. MUMAW' and IRENE NAKONECZNAT \\ Department of Microbiology and Immunology and TDepartment of Pathology, Medical College of Virginia, \\ Virginia Commonwealth University, Richmond, VA 23298, USA
}

\begin{abstract}
Summary. Virulent Salmonella typhimurium, 2000 LD50, were injected intraperitoneally into inbred male $\mathrm{A} / \mathrm{J}$ mice, genetically resistant to salmonella infection. Peritoneal exudate cells were harvested between 5 and $54 \mathrm{~h}$ after infection and examined by electronmicroscopy. Polymorphs were seen ingesting as well as digesting the pathogens as early as $5 \mathrm{~h}$ after infection. Macrophages were equally active in destroying the phagocytosed organisms throughout this period. In the meantime, the proliferation of salmonellae appeared to occur extracellularly in the peritoneal cavity as evidenced by their division.
\end{abstract}

\section{Introduction}

The fate of virulent salmonellae after their ingestion by host phagocytes has become a controversial issue. These pathogens have been classified as facultative intracellular parasites (Collins, 1974; Collins and Campbell, 1982), but we have recently published electronmicrographs showing clearly the degenerative changes in cells of virulent Salmonella typhimurium SR-11 in vivo within polymorphs and macrophages of inbred mice susceptible to salmonella infection (Guo et al., 1986a, b; Lin et al., 1987; Wang et al., 1988). Others have attributed the apparent inconsistency in the interaction between salmonellae and phagocytes to genetic variations of the host (Lissner et al., 1983; Swanson and O'Brien, 1983; van Dissel et al., 1985, 1986). In the present investigation, we examined by electronmicroscopy the digestion of virulent salmonellae within the peritoneal exudate cells of genetically resistant $\mathrm{A} / \mathrm{J}$ mice (Robson and Vas, 1972) to determine whether inflammatory polymorphs and macrophages of genetically resistant and susceptible mice are equally capable of destroying virulent S. typhimurium in vivo.

\section{Materials and methods}

\section{Salmonella typhimurium strain}

The virulent strain SR-11 was used in this study. It was grown in Tryptic Soy Broth (TSB; Difco) at $37^{\circ} \mathrm{C}$ for $6 \mathrm{~h}$ and washed in saline according to the previously

Received 3 Jan. 1989; revised version accepted 4 Apr. 1989.

* Correspondence should be sent to Dr H. S. Hsu. described procedure (Hsu and Radcliffe, 1968). The bacterial suspension was adjusted in a Klett-Summerson photoelectric colorimeter to contain c. $2.5 \times 10^{9}$ viable organisms $/ \mathrm{ml}$ and diluted for injection into mice.

\section{Mice}

The inbred male $\mathrm{A} / \mathrm{J}$ mice weighing $20-25 \mathrm{~g}$ each were purchased from Jackson Laboratories (Bar Habor, ME) and housed in the Central Animal Care Facility of the Medical College of Virginia for at least one week before being used. This strain of mouse is genetically resistant to salmonella infection, with a mean lethal dose (LD50) of $c .10^{4}$ cfu of $S$. typhimurium SR-11 by intraperitoneal (i.p.) challenge.

\section{Infection of mice and collection of peritoneal exudate cells (PEC)}

The procedure was described in detail by Guo et al. (1986a). Two experiments, each with 15 mice, were done. In each case $0.2 \mathrm{ml}$ of a saline suspension containing $c$. $2 \times 10^{7}$ salmonellae was injected i.p. into each mouse. At intervals of $5,24,30,48$ and $54 \mathrm{~h}$ after infection, two or three mice were killed in a chloroform jar. About 6-8 ml of chilled Hanks's solution containing heparin $6 \mathrm{U} / \mathrm{ml}$ were immediately injected into the peritoneal cavity of each mouse, followed by gentle manual agitation of its abdomen. A small incision was made through which the peritoneal washing was aspirated with a glass tube. The contents were transferred into a $15-\mathrm{ml}$ centrifuge tube containing $5 \mathrm{ml}$ of chilled glutaraldehyde $4 \% \mathrm{v} / \mathrm{v}$ in $0.1 \mathrm{M}$ sodium cacodylate buffer and placed in an ice bath. After fixation for $1 \mathrm{~h}$, the tubes were centrifuged at $1300 \mathrm{~g}$ for 30 min to sediment the PEC as well as the extracellular bacteria. The pellet in each tube was resuspended with $1.5 \mathrm{ml}$ of cacodylate buffer. Tubes of PEC collected at the same time interval and without any obvious contam- 
ination by erythrocytes were pooled together. The PEC were washed once with $1.5 \mathrm{ml}$ of $0.1 \mathrm{M}$ sodium cacodylate buffer by centrifugation.

\section{Preparation of PEC for electronmicroscopy}

The washed sediment of fixed PEC and extracellular bacteria was postfixed with osmium tetroxide $1 \% \mathrm{w} / \mathrm{v}$ for $1 \mathrm{~h}$ at room temperature. After dehydration with increasing concentrations of ethanol, the PEC pellets were embedded in Polybed epoxy resin (Polysciences Inc., Warrington, PA). Ultrathin sections were stained with uranyl acetate and Reynold's lead citrate, and examined in a Philips EM400 electronmicroscope.

\section{Results}

\section{Effect of bacterial challenge}

The $\mathbf{A} / \mathbf{J}$ mice were considered to be genetically resistant to salmonella infection. The i.p. injection of $2 \times 10^{7}$ (c. 2000 LD50) bacteria was intended to elicit a rapid inflammatory response in the peritoneal cavity, but it also resulted in a rapid systemic dissemination of the bacteria. The animals usually died, beginning on the third day after infection. When the animals were killed after $54 \mathrm{~h}$, gross pathological changes in the liver and spleen, including minute focal lesions, could be seen.

\section{Degenerative changes in salmonellae within polymorphs}

After i.p. injection of the relatively large dose of $2 \times 10^{7}$ salmonellae, rapid acute inflammation ensued in the peritoneal cavity. By $5 \mathrm{~h}$, neutrophils and eosinophils were present and actively engaged in phagocytic activity. In fig. 1, the neutrophil was in the process of engulfing a bacterium (B). This organism retained its morphological integrity at this stage and its appearance could, therefore, be used for comparative purposes. The neutrophil had already ingested several bacteria which displayed various stages of internal degeneration, ranging from cytologically intact cells (black arrow) to hollow envelopes (open arrows). Fig. 2 depicts another neutrophil with intracellular bacteria. The two adjacent large phagolysosomes $(\mathrm{P})$ contained distinguishable residual bacteria at this plane of sectioning. Many of the remaining ones appeared to be in direct contact with the cytoplasm of the host cell (black arrows) rather than enclosed within a discernible phagolysosome. Some of these bacteria were evidently damaged by external compression and internal condensation of cytoplasmic granules (white arrows). In fig. 3, the eosinophil could be identified by its cigar-shaped granules with a central cross-bar. It also had phagocytosed

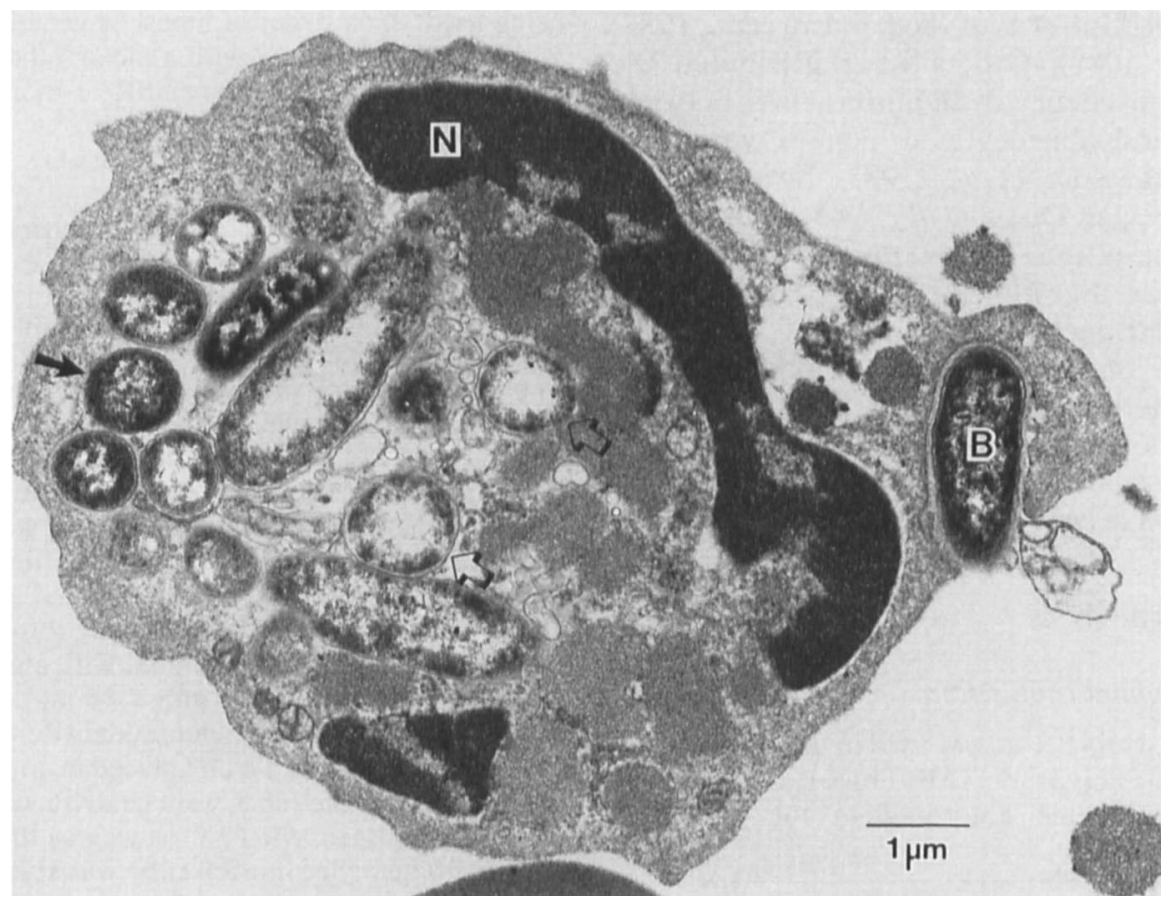

Fig. 1. A neutrophil with ingested salmonellae $5 \mathrm{~h}$ after infection. $\mathrm{N}=$ nucleus; $\mathrm{B}=$ bacterium. Magnification: 14875 . 


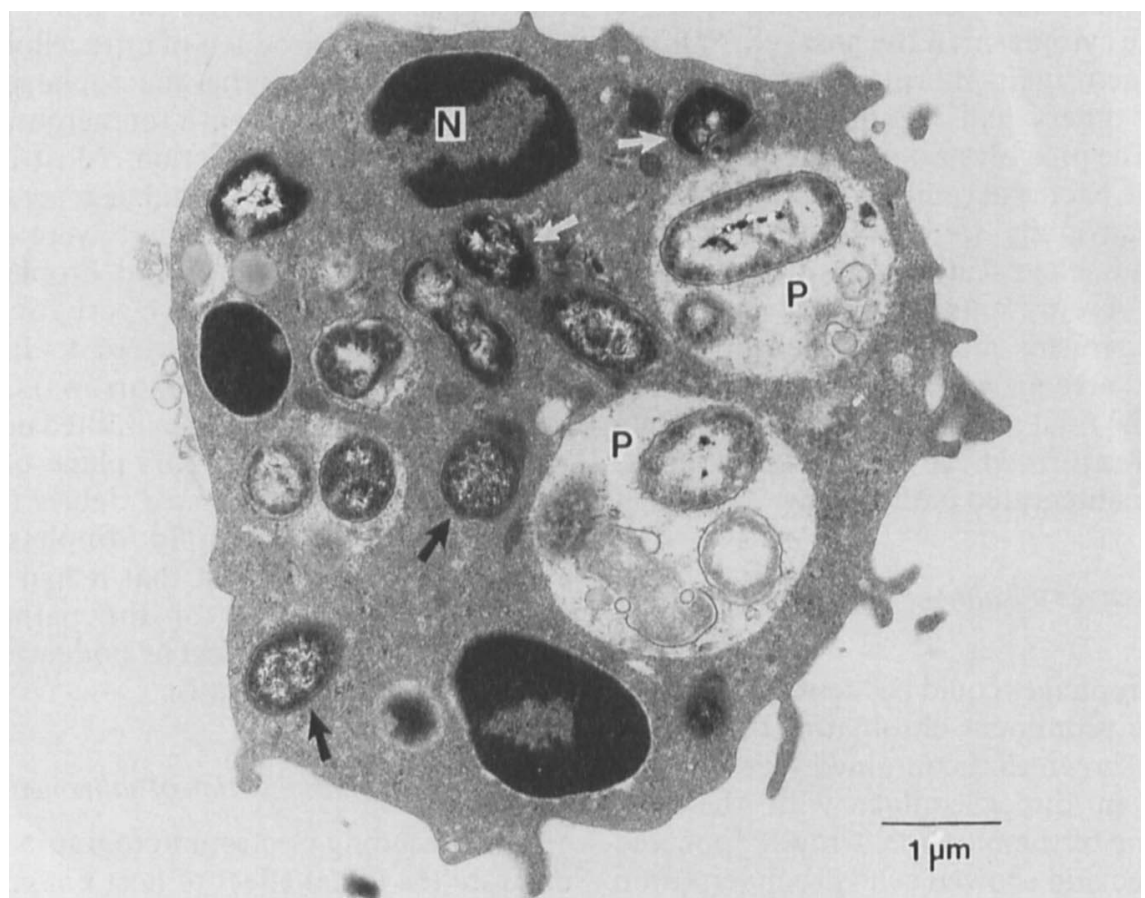

Fig. 2. A neutrophil with ingested salmonellae $5 \mathrm{~h}$ after infection. $\mathrm{N}=$ nucleus; $\mathrm{P}=$ phagolysosome. Magnification: 11900 .

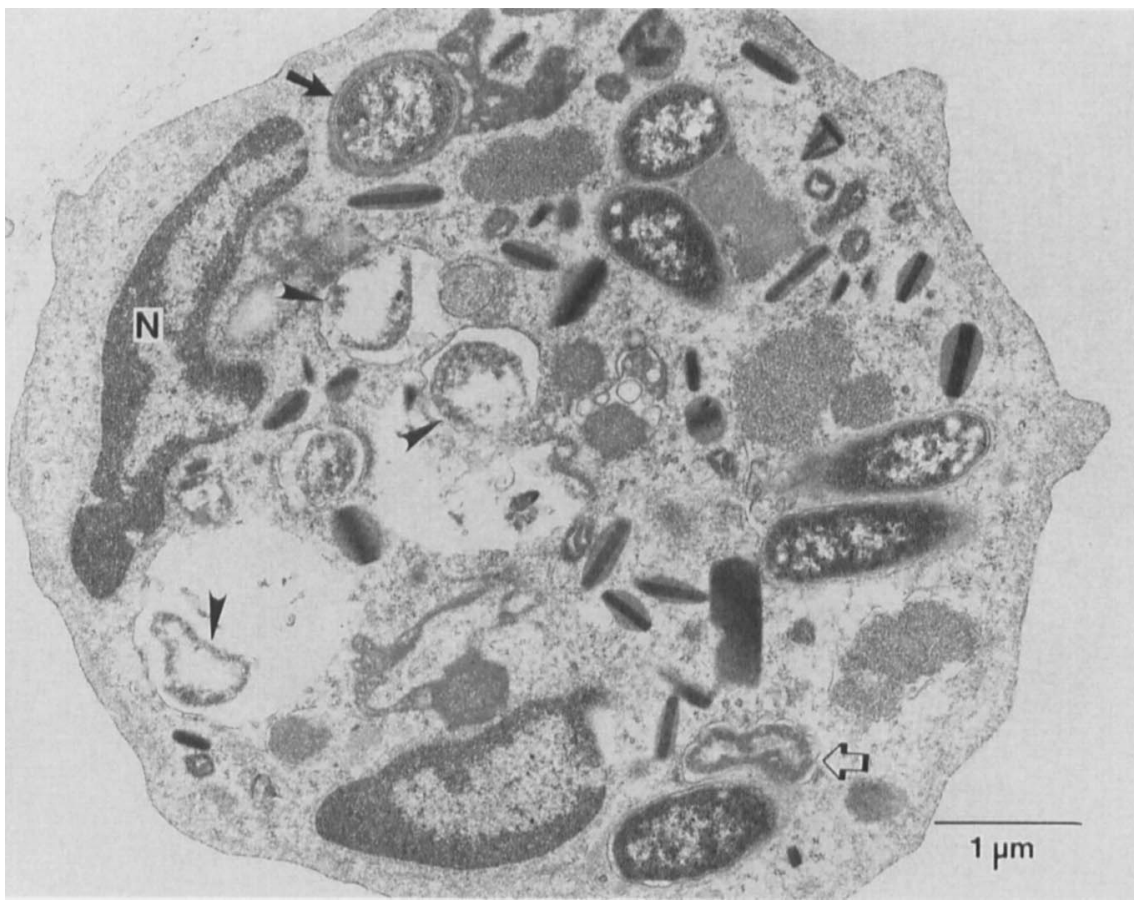

Fig. 3. An eosinophil containing disintegrating bacteria $5 \mathrm{~h}$ after infection. $\mathrm{N}=$ nucleus. Magnification: 14875 . 
several salmonellae, many of which were in direct contact with the cytoplasm of the host cell. While a few still retained their morphological integrity (black arrow), others had begun to disintegrate (open arrow). The phagolysosomes harboured what were likely to be bacterial remains (arrowheads).

At $24 \mathrm{~h}$, neutrophils were seen with a large number of salmonellae scattered throughout their cytoplasm. Fig. 4 represents a typical neutrophil in which some organisms might have recently been ingested (black arrow), while others had already progressed to the final stage of deterioration (open arrows). One area (arrowhead) might represent the debris left by disintegrated pathogens.

\section{Degenerative changes in salmonellae within macrophages}

At $30 \mathrm{~h}$, macrophages could be identified by their nuclei with less prominent chromatin. In fig. 5, a macrophage is shown that contained several damaged bacteria in direct contact with the host cytoplasm. Some of them (white arrows) appeared to be compressed and showed central condensation of cytoplasmic granules and others displayed central vacuolation and peripheral cytoplasmic granulation (open arrows). All of these changes were obviously the result of active antibacterial actions of the phagocyte. The presence of lipid droplets (L) indicates the end products of intracellular digestion. The cytoplasm of another macrophage at $48 \mathrm{~h}$ (fig. 6) was also littered with numerous bacteria at various stages of destruction. Most of them had undergone extensive internal degeneration leaving only a hollow envelope. There were also areas of debris (arrowheads) and lipid droplets (L), both indicative of active digestive activities of the host cell. Several bacteria appeared to have recently entered the host cell (black arrows). By $54 \mathrm{~h}$, the macrophage shown in fig. 7 exhibited no structurally recognisable bacteria at this plane of sectioning. Yet, the pockets of digested debris (arrowheads) and the presence of lipid droplets (L) in its cytoplasm clearly suggest that it had participated in intracellular killing of the pathogens while suffering no injurious effect as evidenced by its welldefined cytoplasmic details.

\section{Extracellular multiplication of salmonellae}

The preceding electronmicrographs clearly demonstrate the lethal effect of host phagocytes on the ingested salmonellae. It would appear reasonable to expect that the pathogenic process of salmonellosis must depend on the extracellular propagation of the organisms. This could be seen in the

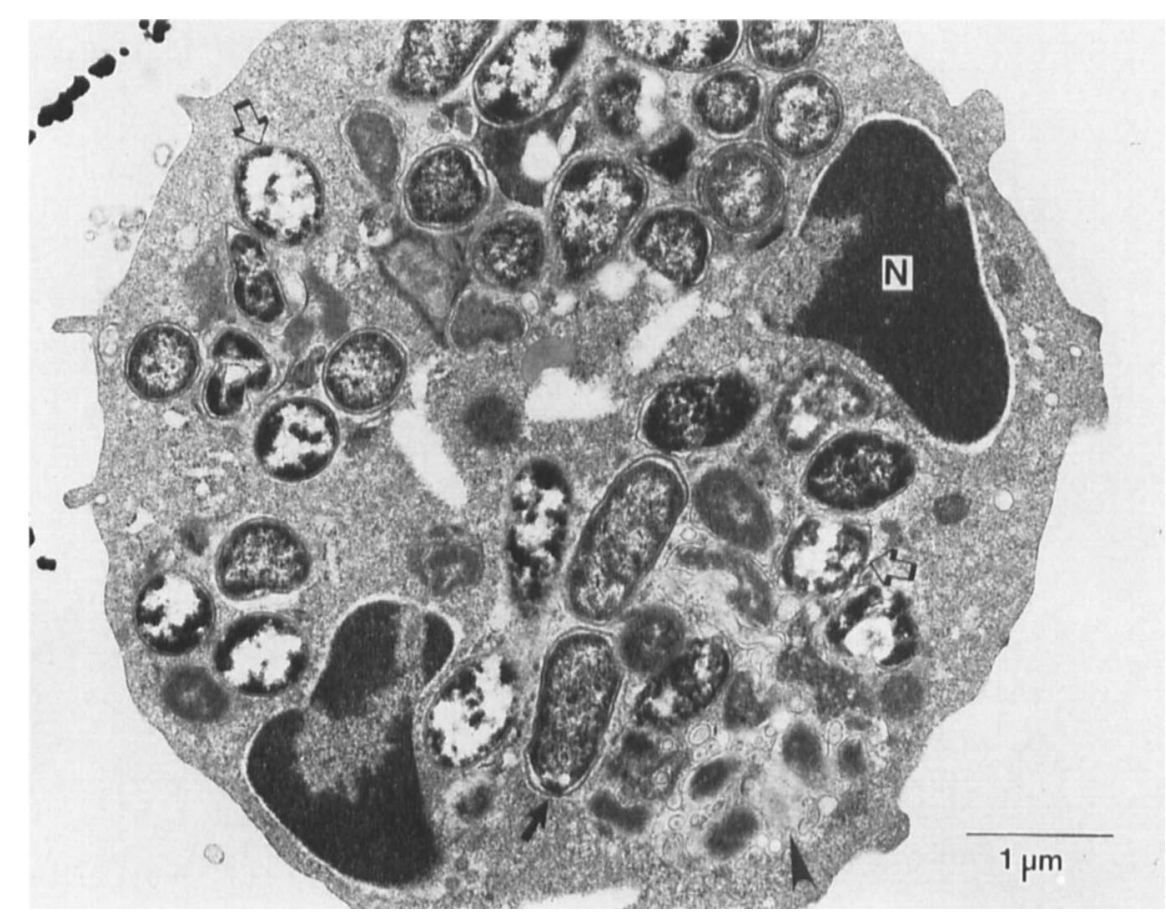

Fig. 4. A neutrophil with scattered intracellular bacteria $24 \mathrm{~h}$ after infection. $\mathrm{N}=$ nucleus. Magnification : 14875 . 


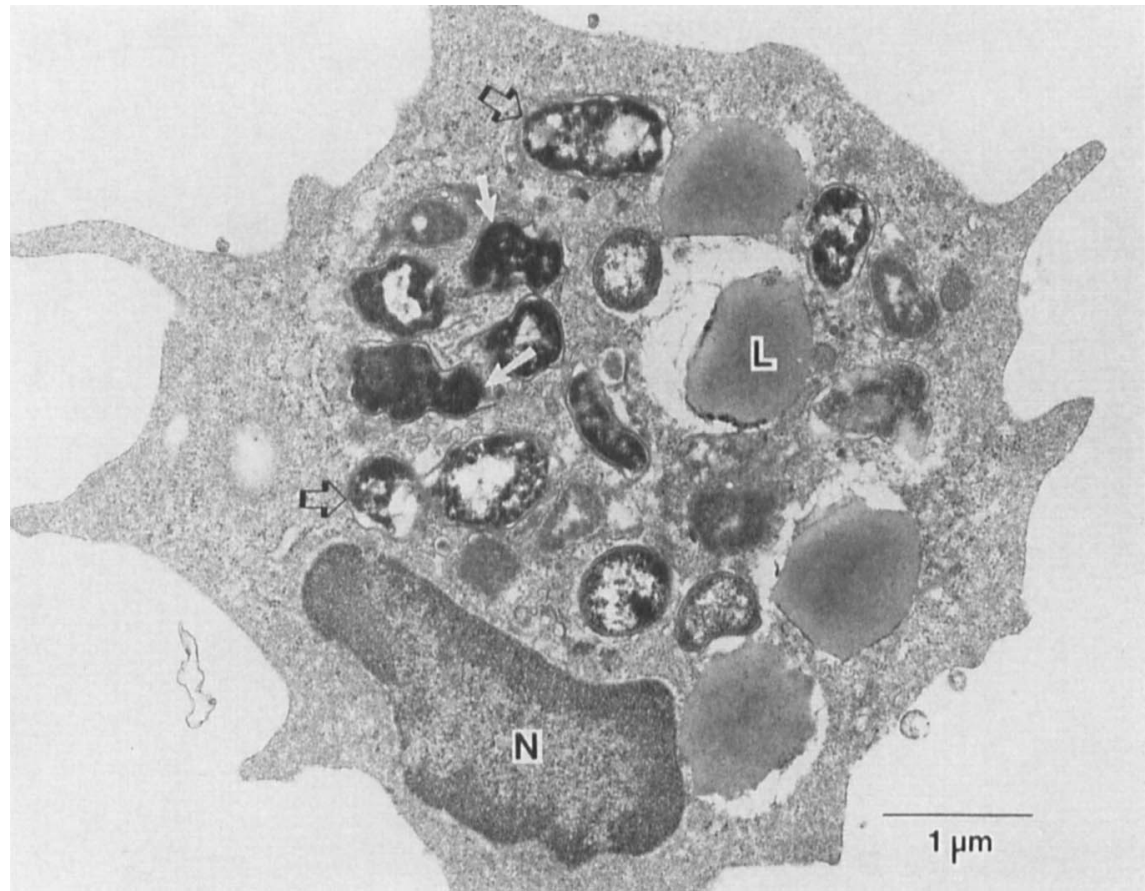

Fig. 5. A macrophage with ingested salmonellae $30 \mathrm{~h}$ after infection. $\mathrm{N}=$ nucleus; $\mathrm{L}=$ lipid droplet. Magnification: 14875 .

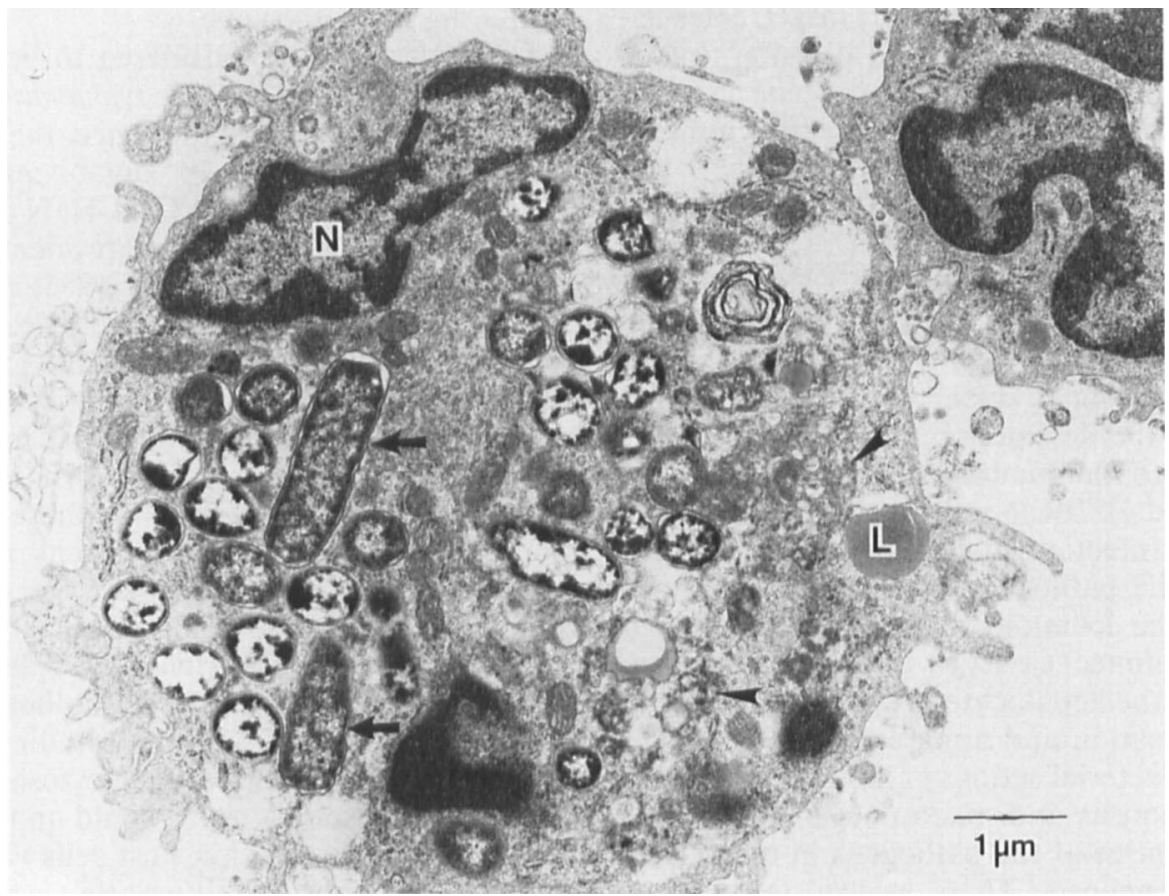

Fig. 6. A macrophage with scattered intracellular bacteria $48 \mathrm{~h}$ after infection. $\mathrm{N}=$ nucleus; L=lipid droplet. Magnification: 11900 . 


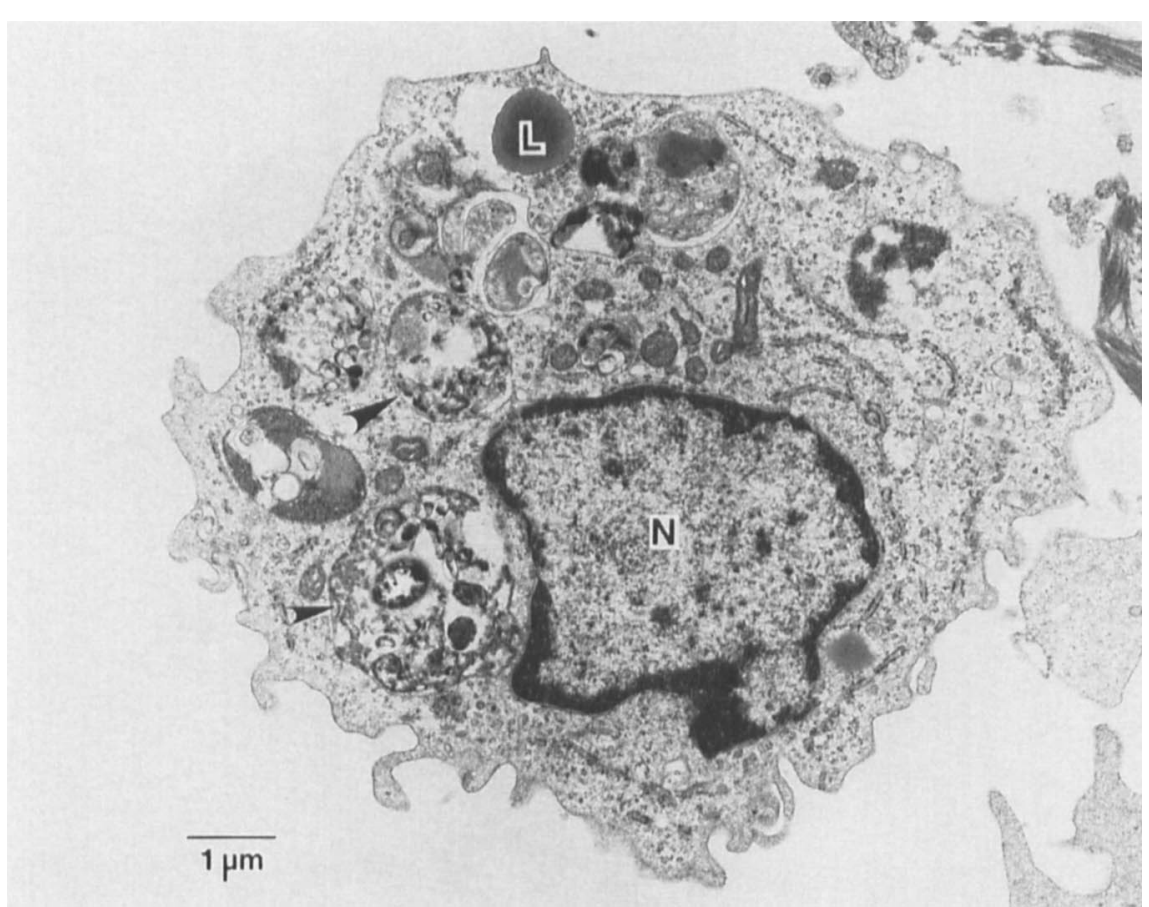

Fig. 7. A macrophage containing digested debris $54 \mathrm{~h}$ after infection. $\mathrm{N}=$ nucleus; $\mathrm{L}=$ lipid droplet. Magnification : 8925 .

peritoneal exudates examined by electronmicroscopy (fig. 8). Some morphologically intact, extracellular bacteria were undergoing division (black arrows). In the meantime, a group of bacteria (open arrow) was being destroyed within the cytoplasm of an adjacent macrophage.

\section{Discussion}

Previous publications from this laboratory (Guo et al., 1986a, b; Lin et al., 1987; Wang et al., 1988) have provided visual evidence by electronmicroscopy to show the destruction of virulent $S$. typhimurium within inflammatory leucocytes, in situ, of $\mathrm{C} 3 \mathrm{H} / \mathrm{HeN}$ and $\mathrm{C} 57 \mathrm{BL} / 6$ mice that are susceptible to salmonella infection. It is also clear from these studies that the pathogens propagated readily in the extracellular locations of the liver and spleen and in the peritoneal cavity of these infected mice. Furthermore, the hepatocytes are a favourable site for their replication and apparently protect them from the antibacterial actions of infiltrating inflammatory polymorphs and macrophages. They may constitute a source of the pathogens in the carrier state of salmonellosis. There is also evidence of salmonellae invading intestinal epithelial cells in orally infected guinea pigs (Takeuchi, 1967). Thus, the non-phagocytic host cells appear incapable of destroying the pathogens.

The A/J mice are considered to be genetically resistant to infection with $S$. typhimurium (Robson and Vas, 1972). In our experience, the LD50 of $S$. typhimurium SR-11 is c. $10^{4}$ organisms, compared to $<10^{2}$ organisms for the $\mathrm{C} 3 \mathrm{H} / \mathrm{HeN}$ and $\mathrm{C} 57 \mathrm{BL} /$ 6 mice. It was reported that resident peritoneal macrophages (van Dissel et al., 1985) and granulocytes (van Dissel et al., 1986) of genetically resistant mice exhibited a greater capacity to inactivate intracellular $S$. typhimurium than those of susceptible mice. Others concurred that resident peritoneal and splenic macrophages of resistant mice kill salmonellae more efficiently than those of susceptible mice and, thus, the pathogens grow better subsequently in the latter cells (Lissner et al., 1983). Hence, the final bacterial accumulation within resident macrophages of liver and spleen depends on the genetic constitution of the host (Swanson and O'Brien, 1983). In all these studies, there was no difference in the rate of phagocytosis by the cells of the two mouse strains. It would appear that the fate of salmonellae within host cells is genetically regulated. A significant observation is that the data from cell culture studies show a continuous decline of salmonellae within macrophages of both geneti- 


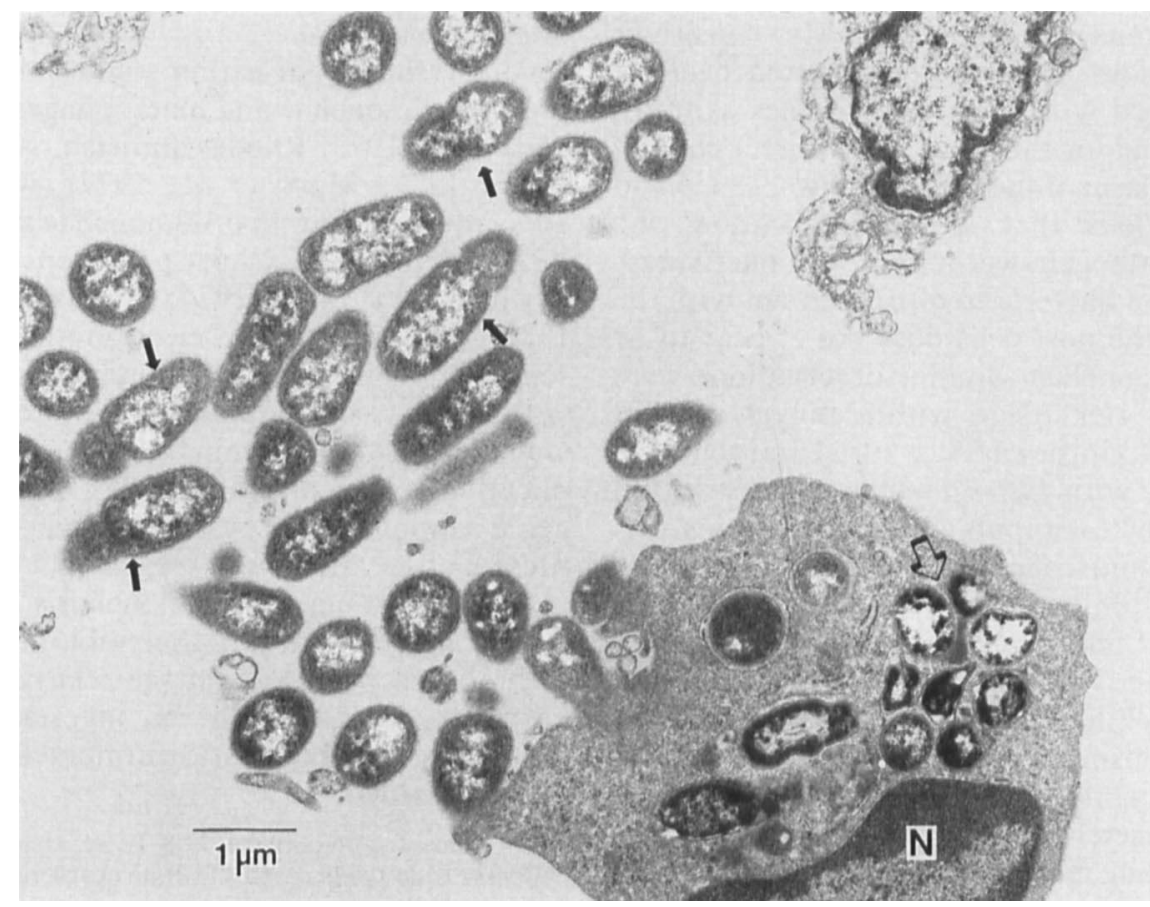

Fig. 8. Extracellular salmonellae in peritoneal washings $24 \mathrm{~h}$ after infection. Arrows point to bacteria undergoing division. $\mathrm{N}=$ nucleus of an adjacent macrophage. Magnification: 10200.

cally resistant and susceptible mice and no net increase of the intracellular bacteria (Lissner et al., 1983; van Dissel et al., 1985). On the other hand, the basic concept of intracellular killing of salmonellae is not shared by other investigators. Baron and Proctor (1984) concluded that murine polymorphs and specific antiserum must act together to kill ingested virulent salmonellae.

The present electronmicroscopic investigation offers a descriptive analysis of the interactions between salmonellae and phagocytes of genetically resistant mice. This approach does not lend itself to a quantitative comparison of the rate of intracellular killing between the resistant and susceptible hosts, because the visual observation is limited to a plane of sectioning across the host cells. Suffice it to say, with all of our published electronmicrographs, (Guo et al., 1986a, b; Lin et al., 1987; Wang et al., 1988), there is ample evidence to establish the contention of a hostile intracellular environment against virulent salmonellae within polymorphs and macrophages of both the genetically resistant and susceptible mice. Once the pathogen is phagocytosed, a fatal outcome appears inevitable, although the possibility that a few pathogens may survive within some phagocytes cannot be com- pletely excluded. Nevertheless, the relative rates of intracellular killing between these two strains of mice are unlikely to be a crucial issue, in view of the overwhelming proliferation of extracellular bacteria. On the other hand, the relative efficiencies with which phagocytes of different mouse strains ingest the pathogen could significantly influence the host resistance to the infection, although the above cited references do not favour such a proposition.

In the present study, a relatively large dose of salmonellae was injected i.p. to elicit a rapid inflammatory response in the peritoneal cavity. The massive influx of polymorphs and macrophages provided the distinct advantage of discerning the interactions of individual phagocytes with the bacteria at the site of infection. We have previously described (Guo et al., 1986a; Lin et al., 1987) two possible sequences of intracellular destruction of salmonellae in the genetically susceptible $\mathrm{C} 3 \mathrm{H} /$ $\mathrm{HeN}$ and C57BL/6 mice. Namely, bacterial degeneration may begin either with central vacuolation and peripheral condensation of cytoplasmic granules leading to the disruption of bacterial envelope, or with peripheral compression of bacterial surface and diffuse condensation of cytoplasmic granules. 
Similar processes were seen here in the genetically resistant $\mathrm{A} / \mathrm{J}$ mice (figs. 2 and 5). Also consistent with our previous findings, the ingested bacteria may be enclosed within phagolysosomes as traditionally believed, or they may be in direct contact with the cytoplasm of the host cells (figs. 2, 3, 5 and 8). It is obvious that in either location, the intracellular pathogens were effectively inactivated. The presence of bacteria in direct contact with the cytoplasm of the host cells does not appear to be unique to salmonellae. Similar observations were reported with rickettsiae within polymorphs of guinea pigs (Rikihisa and Ito, 1982) and found in this laboratory with Listeria monocytogenes within murine phagocytes (unpublished observations).

The electronmicrographs further reveal a dynamic state of antibacterial activities at the site of infection. Host phagocytes arrived within the first $5 \mathrm{~h}$ and were actively destroying the invaders (figs. 1,2 and 3). While a phagocyte was digesting the engulfed organisms, it continued to ingest others (fig. 1). This might explain why a few morphologically intact bacteria could be seen in the host cytoplasm among many disintegrating ones (figs. 1 , 3,4 and 6). By the terminal stage of the infection at 48 and $54 \mathrm{~h}$, individual macrophages were still vigorously destroying the pathogen (figs. 6 and 7). We may add parenthetically that our electronmicroscopic technique provides a direct experimen-

\section{REFERENCES}

Baron E J, Proctor R A 1984 Inefficient in vitro killing of virulent or nonvirulent Salmonella typhimurium by murine polymorphonuclear neutrophils. Canadian Journal of Microbiology 30: $1264-1270$.

Collins F M 1974 Vaccines and cell-mediated immunity. Bacteriological Reviews 38 : 371-402.

Collins F M, Campbell S G 1982 Immunity to intracellular bacteria. Veterinary Immunology and Immunopathology 3: $5-66$.

Guo Y N, Hsu H S, Mumaw V R, Nakoneczna I $1986 a$ Electronmicroscopy studies on the bactericidal action of inflammatory leukocytes in murine salmonellosis. Journal of Medical Microbiology 21 : 151-159.

Guo Y N, Hsu H S, Mumaw V R, Nakoneczna I $1986 b$ Electronmicroscopy studies on the opsonic role of antiserum and the subsequent destruction of salmonellae within murine inflammatory leukocytes. Journal of Medical Microbiology 22 : 343-349

Hsu H S, Mayo D R 1973 Interactions between macrophages of guinea pigs and salmonellae. III. Bactericidal action and cytophilic antibodies of macrophages of infected guinea pigs. Infection and Immunity 8: 165-172.

Hsu H S, Radcliffe A S 1968 Interactions between macrophages of guinea pigs and salmonellae. I. Fate of Salmonella typhimurium within macrophages of normal guinea pigs. Journal of Bacteriology 96: 191-197.

Lin F R, Wang X M, Hsu H S, Mumaw V R, Nakoneczna I tal approach to study the host cell-bacteria interactions in vivo.

As a result of our earlier studies on the interactions of salmonellae and macrophages in vitro (Hsu and Mayo, 1973; Rhodes and Hsu, 1974; Marecki et al., 1975; Mayo et al., 1977), we have long advocated the view that salmonellae are unlikely to be facultative intracellular pathogens, as traditionally claimed (Collins, 1974; Collins and Campbell, 1982). Collectively, the electronmicrographs presented here and elsewhere confirm this contention with direct visual evidence at the site of infection. Our thesis of a predominantly extracellular multiplication versus intracellular destruction of pathogenic salmonellae is best illustrated in fig. 8. The present observations also suggest that the difference in host resistance to salmonellosis between the genetically resistant and susceptible mice is unlikely to be based primarily on the relative abilities of host phagocytes to kill the ingested pathogens. Other aspects of host-parasite interactions will need to be examined.

This study was supported by U.S. Public Health Service grant AI 19434 from the National Institute of Allergy and Infectious Diseases. F.R.L. was a visiting scientist from the Department of Microbiology, Suzhou Medical College, Suzhou, People's Republic of China. We thank R. H. Freeman, Ethel T. Lovings and T. D. Lutz of the Electron Microscope Laboratory of the Department of Pathology, MCV/VCU, for their technical assistance.

1987 Electron Microscopic studies on the location of bacterial proliferation in the liver in murine salmonellosis. British Journal of Experimental Pathology 68: 539-550.

Lissner C R, Swanson R N, O'Brien A D 1983 Genetic control of the innate resistance of mice to Salmonella typhimurium: expression of the Ity gene in peritoneal and splenic macrophages isolated in vitro. Journal of Immunology 131 : 3006-3013.

Marecki N M, Hsu H S, Mayo D R 1975 Cellular and humoral aspects of host resistance in murine salmonellosis. British Journal of Experimental Pathology 56 : 231-243.

Mayo D R, Hsu H S, Lim F 1977 Interactions between salmonellae and macrophages of guinea pigs. IV. Relationship between migration inhibition and antibacterial action of macrophages. Infection and Immunity 18: 52-59.

Rhodes M W, Hsu H S 1974 The effect of kanamycin on the fate of Salmonella enteritidis within cultured macrophages of guinea pigs. Journal of the Reticuloendothelial Society 15: 112.

Rikihisa Y, Ito S 1982 Entry of Rickettsia tsutsugamushi into polymorphonuclear leukocytes. Infection and Immunity 38 : 343-350.

Robson H G, Vas S I 1972 Resistance of inbred mice to Salmonella typhimurium. Journal of Infectious Diseases 126: 378-386.

Swanson R N, O'Brien A D 1983 Genetic Control of the innate resistance of mice to Salmonella typhimurium: Ity gene is expressed in vivo by 24 hours after infection. Journal of Immunology 131 : 3014-3020. 
Takeuchi A 1967 Electron microscope studies on experimental salmonella infection. I. Penetration into the intestinal epithelium by Salmonella typhimurium. American Journal of Pathology 50: 109-136.

van Dissel J T, Leijh P C J, van Furth R 1985 Differences in initial rate of intracellular killing of Salmonella typhimurium by resident peritoneal macrophages from various mouse strains. Journal of Immunology 134: 3404-3410.

van Dissel J T, Stikkelbroeck J J M, Sluiter W, Leijh P C J, van
Furth R 1986 Differences in initial rate of intracellular killing of Salmonella typhimurium by granulocytes of salmonella-susceptible $\mathrm{C} 57 \mathrm{BL} / 10 \mathrm{mice}$ and salmonellaresistant CBA mice. Journal of Immunology 136: 10741080.

Wang X M, Lin F R, Hsu H S, Mumaw V R, Nakoneczna I 1988 Electronmicroscopic studies on the location of salmonella proliferation in the murine spleen. Journal of Medical Microbiology 25: 41-47. 